Superalloys 2012: 12 ${ }^{\text {th }}$ International Symposium on Superalloys

\title{
ENVIRONMENTAL AND DWELL EFFECTS ON THE DAMAGE TOLERANCE PROPERTIES OF ATI 718PLUS ${ }^{\circledR}$ ALLOY
}

\author{
R.M. Kearsey ${ }^{1}$, J. Tsang ${ }^{1}$, S. Oppenheimer ${ }^{2}$, and E. McDevitt ${ }^{2}$ \\ ${ }^{1}$ National Research Council of Canada, Institute for Aerospace Research, Ottawa, ON, Canada, K1A 0R6 \\ ${ }^{2}$ ATI Allvac, 2020 Ashcraft Avenue, Monroe, NC, USA, 28110
}

Keywords: ATI 718Plus ${ }^{\circledR}$ Alloy, Waspaloy, dwell fatigue, environmental damage, FCGR, intergranular fracture

\begin{abstract}
Fatigue crack growth rate (FCGR) and dwell-FCGR tests were conducted at $704^{\circ} \mathrm{C}$ in a vacuum environment and compared with data obtained under lab air conditions for various microstructural conditions of ATI 718Plus ${ }^{\circledR}$ Alloy (718Plus) and Waspaloy. The results indicated that environmental damage has a significant impact on the FCGR characteristics of both alloys, particularly in the near-threshold regime. The dwell fatigue crack propagation behaviour under vacuum conditions displayed identical behaviour irrespective of differences in microstructural features. The observed crack growth rates under vacuum decreased dramatically compared to lab air test results, highlighting the crucial impact of environmental damage on the dwell-fatigue crack propagation resistance of both alloys. The fracture mode for 718Plus was observed to be predominately intergranular in both the FCGR and dwell-FCGR test conditions, with the effect of long-term thermal exposure leading to a larger fraction of transgranular failure. Waspaloy fracture surfaces revealed a predominantly transgranular deformation mode. The fracture surfaces of 718Plus and Waspaloy all exhibited transgranular fracture under vacuum test conditions and were nearly indistinguishable in crack topography. Dynamic embrittlement is believed to be the governing mechanism for intergranular failure of 718Plus leading to grain boundary decohesion. Improvement of dwell-fatigue crack propagation resistance of 718Plus may be strongly related to the coarsening of the $\gamma^{\prime}$ hardening phase, with potential further improvement via implementation of a bimodal $\gamma^{\prime}$ heat treatment. EDX analysis showed that the $\delta$ phase just at the crack tip becomes oxidized and may be a contributing factor in the susceptibility of the grain boundaries during the dwell-FCGR tests. The presence of Nb-rich carbides along the dwell-fatigue crack path of 718Plus was also identified. Carbides located behind the crack front were heavily oxidized and those carbides observed just ahead of the crack tip showed no oxidation. It is believed that oxidation of these $\mathrm{NbC}$ particles near grain boundaries may be linked to the environmental susceptibility of 718Plus during dwell-fatigue crack propagation.
\end{abstract}

\section{Introduction}

New emerging gas turbine engine designs and optimization of existing legacy engines have placed higher temperature and strength demands on hot-section component materials. These demands are partially fueled by the need to sustain more aggressive, longer-duration engine cycles which may contain interactive combinations of time, environment, and cycledependent damage deformation mechanisms. This type of mixedmode damage behaviour must be considered for such gas turbine applications as military transport aircraft, advanced industrial power generation, and marine propulsion. Under these operating conditions, component materials such as turbine disc substrate alloys must inherently incorporate a balance of fundamental material properties such as long-term phase stability, as well as static, cyclic, and dwell-fatigue resistance at these higher temperature-stress regimes. Optimization of these key alloy properties via alloy chemistry and microstructural processing is vital to ensure longer and safer component life with reasonable affordability to the end user. Hence, critical high temperature mechanical properties such as fatigue crack nucleation life, FCGR behaviour, and dwell-fatigue resistance must be optimized and characterized for damage tolerance specifications prior to engine implementation.

A newly developed Ni-base superalloy, ATI 718Plus ${ }^{\circledR}$ Alloy (718Plus) has recently received widespread attention with respect to structural and rotating turbine component applications. The most notable characteristic of this new Ni-base superalloy is its proven temperature capability of $704^{\circ} \mathrm{C}$, making it an ideal candidate for hot-section components [1]. Numerous studies have been completed to date to characterize the fundamental mechanical behaviour of 718Plus; the results of which have shown that the mechanical properties are strongly dependent on alloy addition levels, processing methodologies, and final microstructure $[2,3]$.

More recent work completed by the authors has revealed that the axial-fatigue crack nucleation life for a range of microstructural conditions of 718Plus have all demonstrated superior crack nucleation resistance compared to Waspaloy when tested under dwell and non-dwell conditions to temperatures as high as $704^{\circ} \mathrm{C}$ [4]. It was also shown that the presence of low and high fractions of grain boundary $\delta$ phase had a negligible effect on the crack nucleation resistance of 718Plus. Similarly, a thorough FCGR study completed by the authors revealed that 718Plus and Waspaloy exhibited nearly identical crack propagation resistance in the steady-state regime, with 718Plus presenting a much higher and more favorable threshold stress intensity [5]. However, the dwell-FCGR results conducted in the previous study showed that Waspaloy displayed better steady-state crack growth resistance under peak-tensile dwell-fatigue loading conditions when tested at both $650^{\circ} \mathrm{C}$ and $704^{\circ} \mathrm{C}$. Yet, after $732^{\circ} \mathrm{C}-1000 \mathrm{~h}$ thermal exposure, the dwell-fatigue crack growth resistance of 718Plus did improve to levels more comparable to Waspaloy, indicating possible means for further improving the dwell FCGR properties of the alloy.

Table I: Nominal alloy compositions for 718Plus and Waspaloy used in this study (wt.\%).

\begin{tabular}{|c|c|c|c|c|c|c|c|c|c|c|c|c|}
\hline Alloy & $\mathrm{Ni}$ & $\mathrm{Co}$ & $\mathrm{Cr}$ & $\mathrm{Fe}$ & $\mathrm{Ti}$ & $\mathrm{Al}$ & $\mathrm{Nb}$ & Mo & $\mathrm{W}$ & $\mathrm{C}$ & $\mathrm{P}$ & $\mathrm{B}$ \\
\hline 718Plus $^{(\mathbb{R}}$ & bal. & 8.99 & "17.81 & 9.59 & 0.75 & 1.49 & 5.52 & 2.71 & "1.01 & 0.022 & 0.0056 & 0.0044 \\
\hline Waspaloy & bal. & 13.35 & 19.58 & 0.91 & 3.05 & 1.38 & 0.02 & 4.18 & 0.04 & 0.036 & 0.0018 & 0.0073 \\
\hline
\end{tabular}


During thermal exposure, two significant microstructural changes were observed: 1 ) the formation and growth of the $\delta$ phase and 2) coarsening of the ultrafine $\gamma^{\prime}$ hardening phase [6]. It was shown that the $\delta$ phase had minimal affect on the dwell-fatigue resistance of 718Plus; therefore, the improved dwell-fatigue crack propagation resistance was most likely related to the observed coarsening of the $\gamma^{\prime}$ hardening phase, which was observed to double in size after thermal exposure [4]. This structure results in crack-tip blunting due to the significantly reduced plastic deformation resistance of the over-aged precipitate condition. In addition, grain boundary oxidation kinetics or possibly dynamic embrittlement along the grain boundaries were also suspected to be major contributing factors to the overall dwell-fatigue resistance of 718Plus. The purpose of this paper is to investigate and elucidate the synergistic effects of dwell and environmental factors on 718Plus via dwell FCGR tests performed under controlled-vacuum conditions and identical interrupted tests performed in a laboratory air environment.

\section{Materials}

The 718Plus and Waspaloy materials used in this study were removed from single VIM/VAR heats that were converted using standard forging methods to $13.7 \mathrm{~cm}$ final diameter billets. The nominal composition of each alloy is shown in Table I. Both materials were subsequently sectioned into specimen blanks which were removed from the mid-radius region of each billet. These blanks were then thermally processed to achieve various microstructural conditions. It should be noted that all heat treatments were performed below pertinent precipitate solvus temperatures, thereby eliminating any adverse affect from grain growth.

Heat treatment details for the various material conditions of 718Plus and Waspaloy used in this study are provided in Table II. The conditions investigated include the standard heat treatment condition, HT1, with a retained fine equiaxed grain structure, a $\gamma^{\prime}$ precipitate phase fraction between 0.19 to 0.21 and a small platelike $\delta$ phase fraction located primarily along the grain boundaries. HT2 was incorporated to study the effects of extensive thermal exposure on the microstructural and mechanical properties of 718Plus. In addition, comparative mechanical testing was also performed on Waspaloy prepared in the standard heat treatment condition, W1.

Table II: Heat treatment conditions of 718Plus and Waspaloy.

\begin{tabular}{lll}
\hline Alloy & ID & Heat treatment details $\left({ }^{\circ} \mathrm{C}\right)$ \\
\hline \hline 718Plus ${ }^{\circledR}$ & HT1 & $968^{\circ} \mathrm{C} 0.5 \mathrm{~h}, \mathrm{RAC}$ \\
& & $788^{\circ} \mathrm{C} 8 \mathrm{~h}, \mathrm{FC} @ 38^{\circ} \mathrm{C} / \mathrm{h}$ \\
& & $704^{\circ} \mathrm{C} 8 \mathrm{~h}, \mathrm{AC}$ \\
\cline { 2 - 3 } Waspaloy & $\mathrm{HT} 1+732^{\circ} \mathrm{C} 1000 \mathrm{~h}, \mathrm{AC}$ \\
\cline { 2 - 3 } & $\mathrm{HT} 2$ & $1018^{\circ} \mathrm{C} \mathrm{h}, \mathrm{WQ}$ \\
& & $843^{\circ} \mathrm{C} 4 \mathrm{~h}, \mathrm{AC}$ \\
& & $760^{\circ} \mathrm{C} 16 \mathrm{~h}, \mathrm{AC}$ \\
\hline where: & (RAC) rapid air cooling, (FC) furnace cooling, \\
& (AC) air cooling, (WQ) water quench
\end{tabular}

Microstructural Properties

A detailed metallographic analysis was performed on all heat treatment conditions with more comprehensive results available in literature $[4,7]$. The typical variation in grain structure for both billet materials demonstrated uniform equiaxed grain morphology with grain size ranging between 21 to $64 \mu \mathrm{m}$. Sample micrographs illustrating the extremes of this grain size range of 718Plus are shown in Figure 1(a) and (b). These micrographs also show the presence of the incoherent $\delta$ phase precipitates primarily decorating grain boundaries in a combination of orientations (i.e. parallel, perpendicular and at an angle to the grain boundaries) with negligible precipitate levels at intragranular or twin boundaries sites. Figure 1(c) shows the $\delta$-free Waspaloy microstructure of comparable equiaxed grain size.
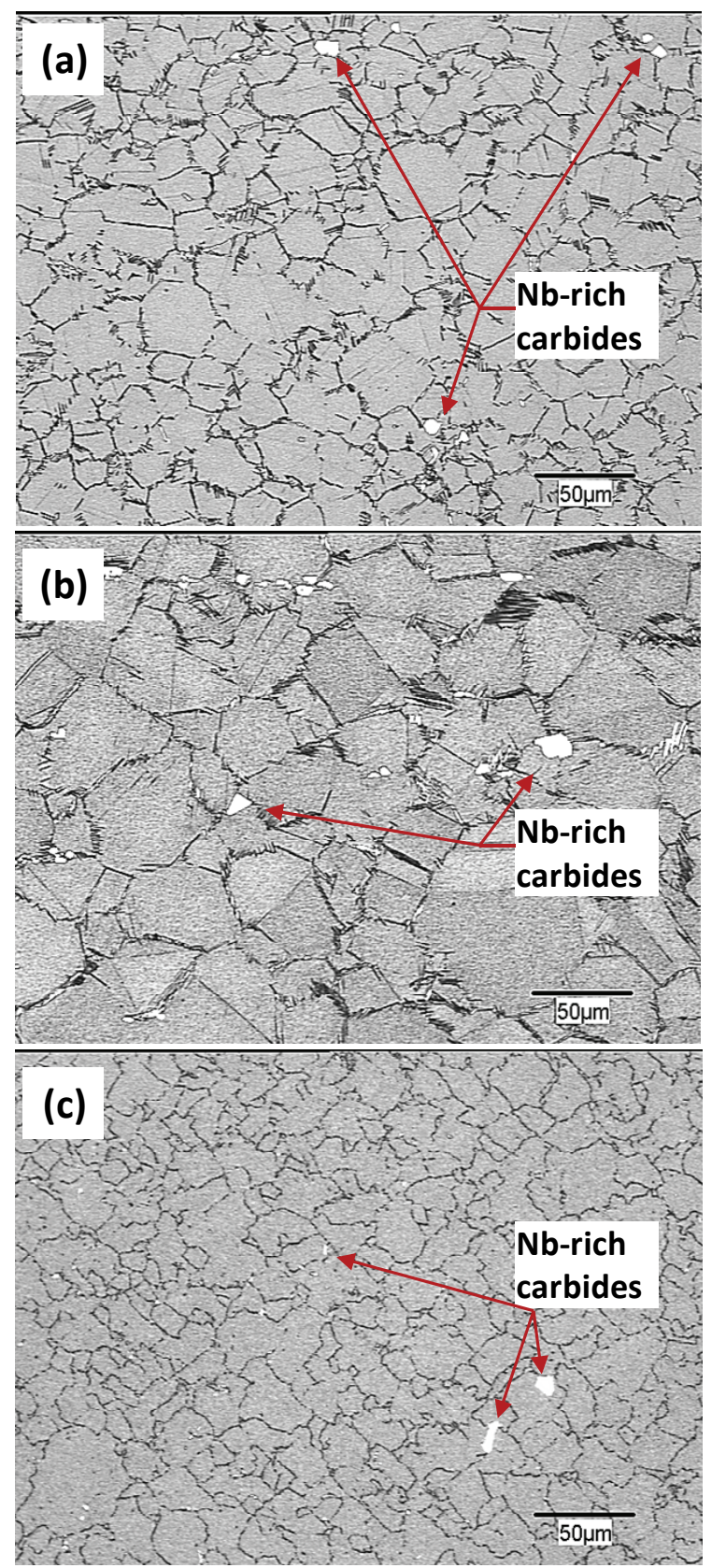

Figure 1: Grain structure of (a) HT1, (b) HT2, and (c) W1. An electrolytic etchant was used to reveal the grain structure of both alloys. It should be noted that in these optical micrographs, the delta phase appears as the dark coloured, needle-like phase along the grain boundaries. 
Shown in Figure 2 is an ultra high resolution secondary electron image illustrating the typical plate-shaped morphology of the orthorhombic $\delta$ phase present in 718Plus, noticeably surrounded by the coherent $\gamma^{\prime}$ strengthening phase. For convention, intragranular $\gamma^{\prime}$ precipitates larger and smaller than $100 \mathrm{~nm}$ were classified as secondary and tertiary $\gamma^{\prime}$ respectively. There were no primary $\gamma^{\prime}$ precipitates observed along the grain boundaries in either 718Plus or Waspaloy material conditions. Higher magnification images of the fine $\gamma^{\prime}$ phase for each 718Plus condition are shown in Figure 3, revealing the uniformly distributed, near-spherical precipitate morphology. It is apparent from this figure that extensive thermal exposure of HT2 has resulted in significant precipitate coarsening. In comparison, Figure 3(c) and (d) show that Waspaloy-W1 exhibits a bimodal, spherical precipitate structure with the secondary $\gamma^{\prime}$ size approximately three times larger than the tertiary. Comparing the precipitate sizes, it is apparent that the tertiary $\gamma^{\prime}$ size for Waspaloy is of the same magnitude as the average $\gamma^{\prime}$ size observed in 718Plus. Quantitative microstructural details for each material condition have been summarized in Table III.

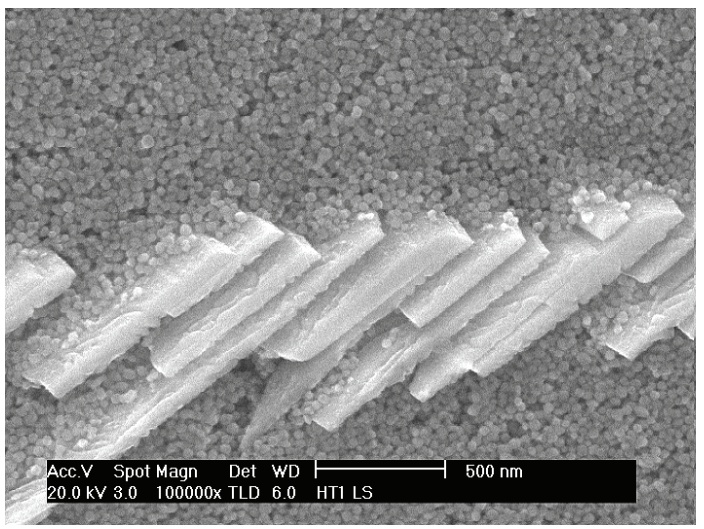

Figure 2: Typical plate-shaped $\delta$ precipitate structure surrounded by fine $\gamma^{\prime}$ phase observed in all 718Plus material conditions $(\gamma$ matrix was removed during etching).
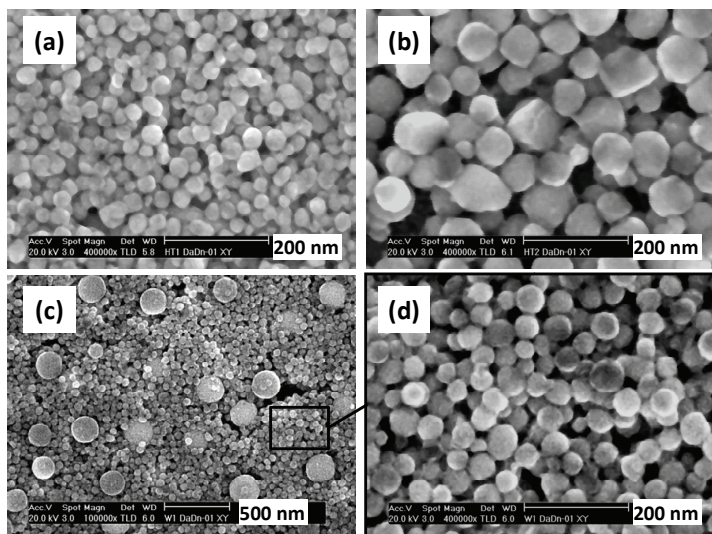

Figure 3: Spherical $\gamma^{\prime}$ morphology observed in 718Plus (a) HT1 and (b) HT2 conditions. (c) Bimodal $\gamma^{\prime}$ distribution of Waspaloy W1 showing larger secondary and very fine tertiary $\gamma^{\prime}$ size with higher magnification inset of (d) W1 tertiary $\gamma^{\prime}$. ( $\gamma$ matrix was removed during etching).
Table III: Summary of microstructural features for 718Plus and Waspaloy material conditions.

\begin{tabular}{|c|c|c|c|c|c|}
\hline \multirow{2}{*}{ Alloy } & \multirow{2}{*}{ ID } & \multicolumn{2}{|c|}{$\delta$ fraction } & \multicolumn{2}{|c|}{$\gamma^{\prime}$ size $(\mathrm{nm})$} \\
\hline & & $A_{f}$ & std. dev. & secondary & tertiary \\
\hline \multirow[t]{2}{*}{ 718Plus } & HT1 & 0.065 & \pm 0.010 & $\mathrm{n} / \mathrm{a}$ & 27.6 \\
\hline & HT2 & 0.059 & \pm 0.009 & $n / a$ & 59.6 \\
\hline Waspaloy & W1 & $\mathrm{n} / \mathrm{a}$ & $\mathrm{n} / \mathrm{a}$ & 144.4 & 40.5 \\
\hline Grain & $\begin{array}{l}\text { H.T. } \\
\text { H.T. }\end{array}$ & $\mid S^{(B)}$ & $\begin{array}{l}\text { t, } 24 \mathrm{tc} \\
\text { et, } 20 \mathrm{t}\end{array}$ & $\begin{array}{l}\text { (ASTM } 5 \\
\text { (ASTM }\end{array}$ & $\begin{array}{l}7.5) \\
\text { to } 8)\end{array}$ \\
\hline
\end{tabular}

\section{Experimental Procedures}

The FCGR and dwell-FCGR tests were conducted using a standard compact-tension specimen with crack growth rates monitored using a direct-current potential drop (DCPD) method. All test procedures and parameters conformed to the ASTM E647 test standard [8]. All of the tests were conducted at $704^{\circ} \mathrm{C}$ $\left(1300^{\circ} \mathrm{F}\right)$ in an inert, high-vacuum $\left(\sim 10^{-7}\right.$ torr) environment and at a stress ratio, $\mathrm{R}=0.10$.

The dwell-FCGR tests were carried out with a 100 second dwell at peak-tensile load with a 1.5 second ramp to and from the maximum load, for a total period of 103 seconds and an effective frequency of $0.00971 \mathrm{~Hz}$. The FCGR tests were carried out at a frequency of $3 \mathrm{~Hz}$ and were split into two segments; stress intensity factor, K, K-decreasing (i.e. load shedding) and Kincreasing (i.e. constant load). The K-decreasing portion of the test was performed using a stress intensity factor gradient of $\mathrm{C}=$ $236.2 \mathrm{~m}^{-1}\left(-6 \mathrm{in}^{-1}\right)$ whereas the dwell-FCGR and K-increasing segment of the FCGR tests were conducted using a constant maximum load, $\mathrm{P}_{\max }$; allowing the growth of the fatigue crack to naturally increase the stress intensity factor.

Due to the large differences in dwell-FCGR properties observed by the authors in previous studies conducted in lab air conditions [5], additional interrupted dwell-FCGR tests were performed to investigate the effect of environmental damage on the dwellfatigue crack propagation rates. These tests were conducted in an identical manner as described for the preceding vacuum tests, except for the presence of a lab air environment and that the tests were interrupted during steady-state crack propagation well within the Paris regime of each test. These specimens were then sectioned and mounted for metallographic and fractographic examination.

Following each test, a traveling optical microscope was used to measure the actual crack size on the fracture surface and corrections were made to the original crack growth rate data. Postfracture analysis was performed on the FCGR and dwell-FCGR tests, including the interrupted dwell-FCGR specimens, using scanning electron microscopy. The analysis included using secondary (SE), backscattered electron (BSE), and through-lens (TLD) detectors as well as energy dispersive $\mathrm{x}$-ray (EDX) analysis.

\section{Results and Discussion}

As mentioned previously, FCGR and dwell-FCGR tests were conducted in a vacuum environment and these results will be compared with data obtained under identical test parameters [5] with the exception of a lab air environment. The results will then 
be examined to elucidate the environmental effect and its impact on the two test conditions.

\section{FCGR and dwell-FCGR Behaviour}

Previous studies have shown that the 718Plus alloy and Waspaloy have nearly identical steady-state crack growth characteristics but the 718Plus alloy has a significantly higher threshold to fatigue crack propagation [5]. The vacuum FCGR test results obtained in this study, shown in Figure 4, demonstrate that under an inert environment, the FCGR behaviour of 718Plus and Waspaloy are identical in the near-threshold region and in the steady-state Paris regime. Upon comparison with the results obtained in lab air [5] that are also plotted in Figure 4, it can be seen that the environmental effects have a significant impact on the FCGR characteristics of both alloys, particularly in the near-threshold regime. It appears that the higher threshold behaviour observed in the lab air tests is a result of an oxidation-related phenomenon $[9,10]$.

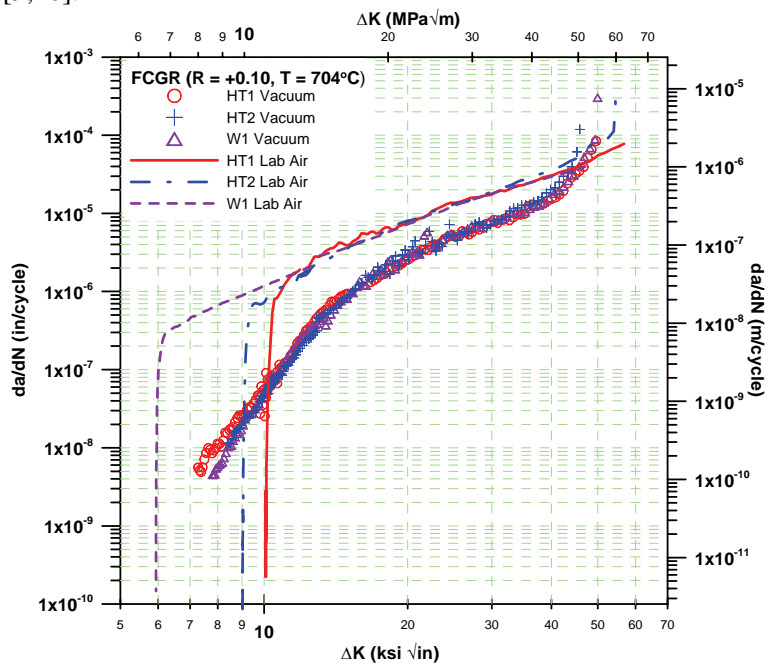

Figure 4: Vacuum FCGR test results and lab air FCGR test data obtained from the same material in a previous study [5].

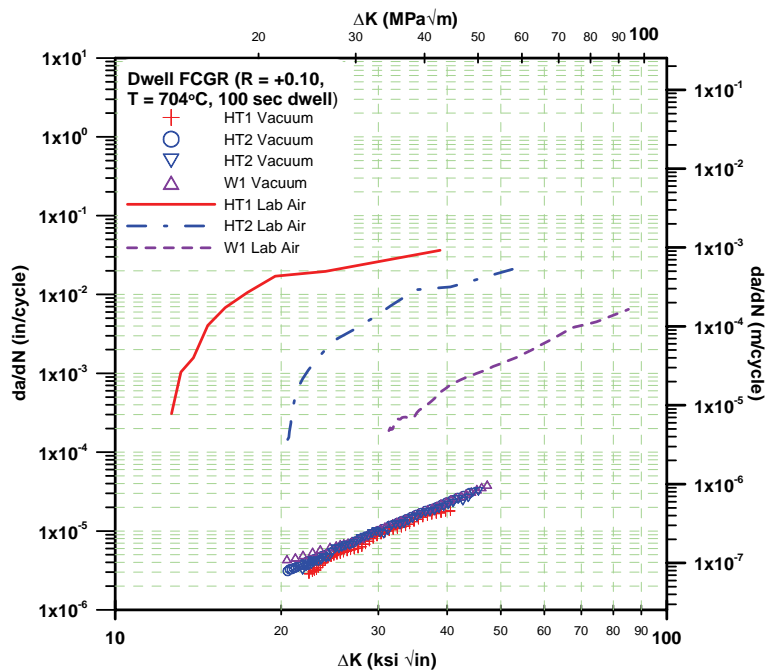

Figure 5: Vacuum dwell-FCGR test results and lab air test data obtained from the same material in a previous study [5].
The dwell-FCGR results for the tests in this study as well as the results from a previous study of identical dwell-FCGR tests conducted in lab air [5] are shown in Figure 5. It can be seen that while the lab air tests show a substantial difference between the dwell fatigue behaviour of HT1, HT2 and W1, under vacuum conditions, their behaviour is identical. For all three material conditions tested under vacuum the crack growth rates decreased dramatically, highlighting the crucial impact of environmental damage on the dwell-fatigue crack propagation resistance of both 718Plus and Waspaloy.

Post-Fracture Analysis

Post-fracture analysis of the vacuum FCGR and dwell-FCGR specimens was performed and compared with the fracture surfaces of identical tests performed in lab air. Representative secondary electron images of each condition can be found in Figure 6 and Figure 7 for the FCGR and dwell-FCGR specimens, respectively.

It was found that the fracture mode for HT1 was predominately intergranular in both the FCGR and dwell-FCGR test conditions, whereas HT2 exhibited more transgranular failure than HT1 under non-dwell FCGR testing circumstances. Examining the HT2 dwell fracture surfaces revealed that it also exhibited an intergranular topography, comparable to HT1 albeit to a lesser degree. The Waspaloy non-dwell FCGR specimen revealed a predominantly transgranular fracture surface, significantly different than the 718Plus HT1 and HT2 conditions. The observed differences between Waspaloy and 718Plus continue in the dwell-FCGR specimens with the W1 dwell fracture surface exhibiting transgranular fracture morphology, although to a lesser extent than in the non-dwell FCGR specimens. These results substantiate what was found in previous studies $[5,11]$.

After examination of the fracture surfaces of the FCGR and dwellFCGR tests that were performed in vacuum, it was observed that the differences in fracture mode that were observed for the lab air tested specimens were no longer present. As can be seen in Figure 6 and Figure 7, the fracture surfaces of HT1, HT2 and W1 all exhibited transgranular fracture and displayed nearly identical crack topography. The identical fracture morphology in both the FCGR and dwell-FCGR test specimens would also explain why the measured crack growth rates in both conditions under a vacuum environment were also identical, as can be seen in Figure 4 and Figure 5.

Further evidence of the degree of intergranular or transgranular fracture morphology can be seen in the cross-sectional examination of the interrupted dwell-FCGR tests conducted in lab air, shown in Figure 8. As can be seen from this figure, the crack propagation in the interrupted HT1 test shows a very tortuous crack path that is indicative of intergranular fracture as the crack propagates along the grain boundaries. In comparison, Waspaloy shows a significantly more planar crack path, indicating a much more transgranular fracture mode as the fatigue crack propagates through the grains of the W1 microstructure, rather than intergranularly. The interrupted HT2 specimen, as shown in Figure 8, shows a crack morphology similar to $\mathrm{W} 1$, thus indicating a greater extent of transgranular fracture. However, upon closer inspection using the SEM BSE detector, the observed fracture morphology of HT2, as shown in Figure 9, is actually predominately intergranular just to a lesser degree than HT1, as mentioned earlier. Dwell fatigue cracking in HT2 occurred 
primarily along the grain boundaries, which are populated by the $\delta$ phase as identified during the metallographic analysis.
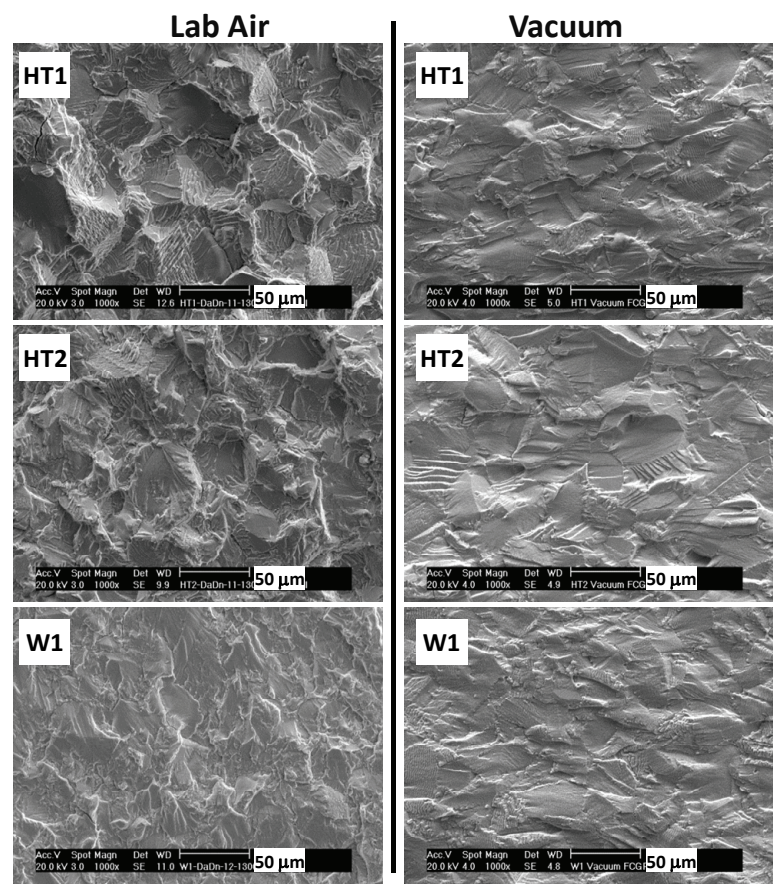

Figure 6: Comparison of fracture mode between lab air and vacuum FCGR tests performed at $704^{\circ} \mathrm{C}$ at $3 \mathrm{~Hz}$.
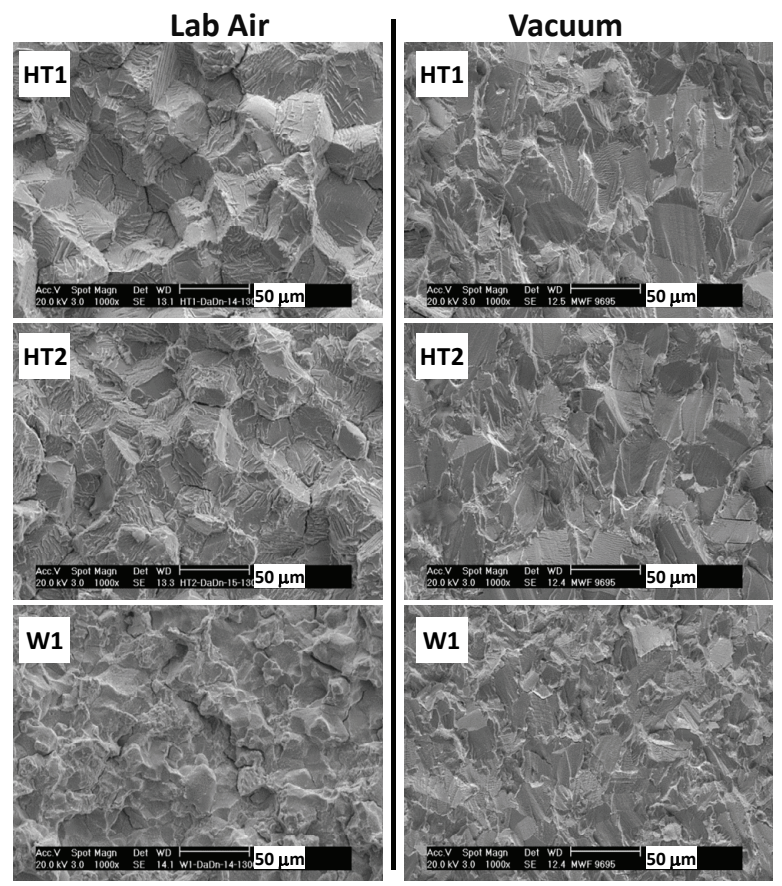

Figure 7: Comparison of fracture mode between lab air and vacuum dwell-FCGR tests performed at $704^{\circ} \mathrm{C}$ with 100 s dwell.
For Ni-based superalloys such as 718Plus and Waspaloy, fatigue crack propagation may be either time or cycle dependent or some combination thereof, largely governed by such variables as temperature and environment $[12,13]$. The main mechanism for crack propagation in a cycle-dependent case is the cyclic plastic deformation immediately ahead of the crack tip, usually resulting in a transgranular type of fracture [4]. In the case of timedependent fatigue crack propagation, environmental effects (i.e. oxidation) and creep are the dominant damage mechanisms and these effects are diffusion-controlled [12,13]. As such, timedependent crack propagation is typically intergranular because the grain boundaries are preferential locations for higher diffusivity [12]. Based on the observed fracture morphology of HT1, HT2, and W1, the differences in FCGR and dwell-FCGR between 718Plus and Waspaloy may be attributed to crack propagation in 718Plus is predominantly a time-dependent process, whereas in Waspaloy, cycle-dependent damage mechanisms dominate during crack propagation.

It has been reported that the main environmental effects of timedependent fatigue crack propagation in Ni-base superalloys is dynamic embrittlement and oxidation of grain boundaries and other microconstituents such as $\gamma^{\prime}$ and grain boundary carbides, the latter two of which are stress-assisted mechanisms $[12,13,14]$. The dynamic embrittlement process, which is believed to be the governing mechanism for intergranular failure of Ni-base superalloys, involves short-range atomic oxygen diffusion (or other gaseous species) into the grain boundaries, which lead to grain boundary decohesion [14].

A closer examination of the 718Plus HT1 and HT2 interrupted dwell-FCGR coupons confirms that the preferred crack path was along the susceptible (i.e. favorably oriented) grain boundary $\delta$ phase, as shown in Figure 9, thereby creating an intergranular fracture surface. Waspaloy, which contains no $\delta$ phase, was not as vulnerable along its grain boundaries and produced a predominately transgranular fracture surface. It appears that although the presence of the grain boundary $\delta$ phase in 718Plus has excellent benefits with respect to improving high-temperature notch-rupture ductility along the grain boundaries [1], it may play some role in preferential intergranular cracking when compared to Waspaloy. However, it was shown in previous work that the presence of varying amounts of grain boundary $\delta$ phase $\left(0.06 \mathrm{~A}_{\mathrm{f}}\right.$ to $0.12 \mathrm{~A}_{f}$ ) in four microstructural variants of 718 Plus had minimal effect on the dwell-fatigue crack propagation resistance. In fact they showed identical dwell-FCGR behaviour [5,7]. Recent studies performed by Gabb et al., have examined the effect of modifying the microstructure of 718Plus via grain boundary engineering (GBE) practices while maintaining grain boundary size features [15]. In their work, they determined that the incorporation of a $\delta$ phase heat treatment, thereby promoting $\delta$ along the grain boundaries, imparted superior dwell-FCGR properties when compared to the $\delta$-free 718 Plus microstructure [15]. What is also significant about their findings is that the $\delta$ containing 718Plus heat treatment condition displayed a bimodal $\gamma^{\prime}$ distribution of $\sim 30 \mathrm{~nm}$ and $130 \mathrm{~nm}$. The fracture modes associated with these bimodal $\gamma^{\prime}, \delta$-containing microstructures also exhibited a larger fraction of transgranular deformation when compared to the unimodal, $\delta$-free structures investigated [15]. Therefore, the observed improved dwell-fatigue crack propagation resistance of HT2 in the present study may be strongly related to the coarsening of the $\gamma^{\prime}$ hardening phase during thermal exposure, with potential further improvement in dwell-FCGR properties via 


\section{$704^{\circ} \mathrm{C}, 100$ s dwell-FCGR, Lab Air}
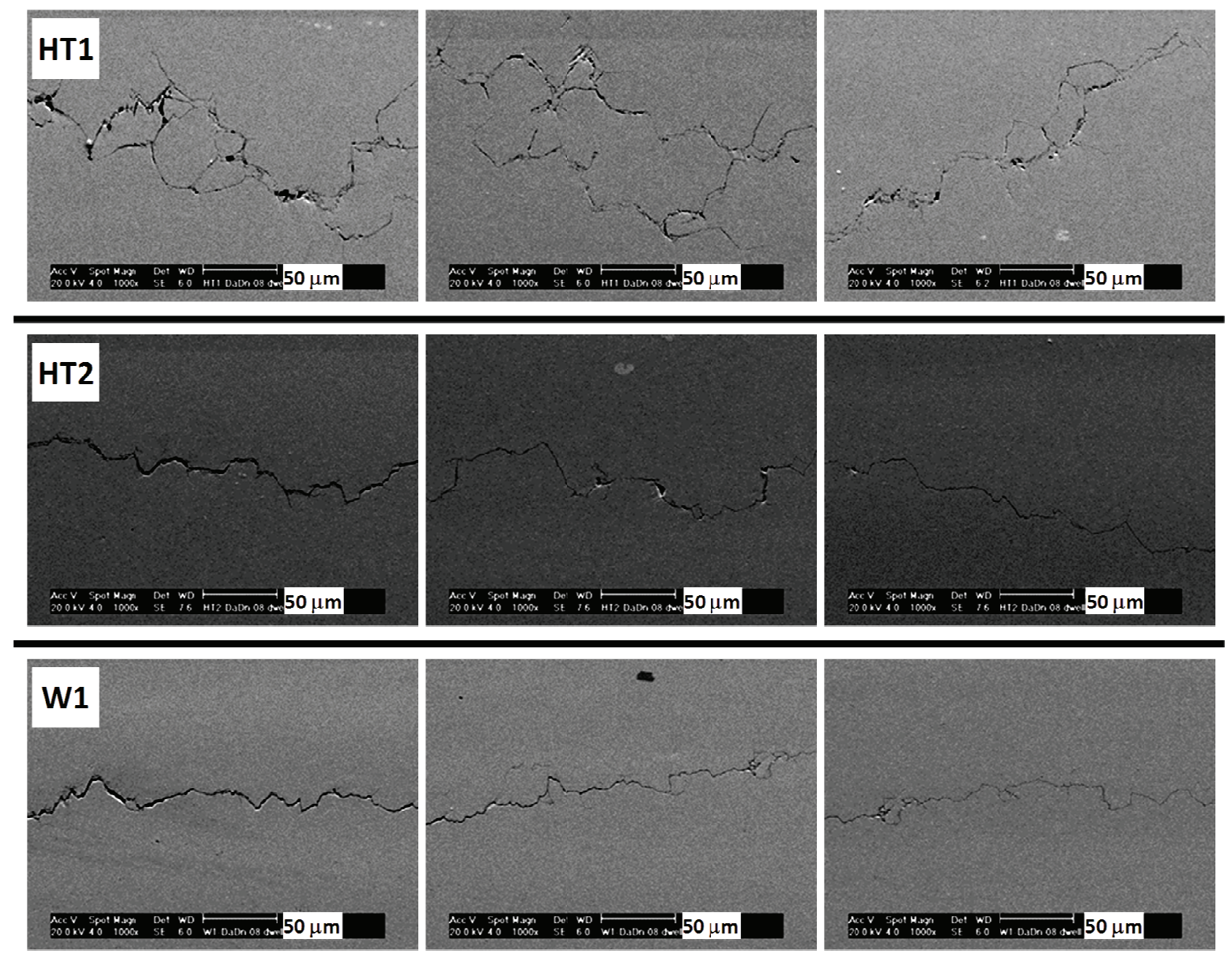

Figure 8: Fracture topography for the HT1, HT2, and W1 interrupted dwell-FCGR tests conducted in lab air using SE imaging.

implementation of a bimodal $\gamma^{\prime}$ heat treatment. It is also noteworthy that the bimodal $\gamma^{\prime}$ size distribution observed by Gabb et al. [15], is comparable to the distribution observed in the present study for Waspaloy-W1 ( 40nm and $140 \mathrm{~nm})$, which as discussed earlier exhibits a larger fraction of transgranular deformation during dwell-FCGR testing.

EDX analysis was conducted to verify the presence of the $\delta$ phase along the dwell fatigue cracks in 718Plus. As can be seen by the EDX map in Figure 10, the Nb-rich $\delta$ phase, particularly the $\delta$ phase parallel to the grain boundary, is present within, as well as just ahead of, the propagating dwell fatigue crack. It is unclear whether the $\delta$ phase just at the crack tip has become oxidized and whether that could be a contributing factor in the susceptibility of the $\delta$ phase parallel the grain boundaries during the dwell-FCGR tests. Although the EDX map is qualitative in nature, the detected oxide within the crack tip was observed to be predominantly rich in $\mathrm{Nb}$ and $\mathrm{O}$, and depleted in both $\mathrm{Cr}$ and $\mathrm{Fe}$ concentration. In comparison, the inert, vacuum dwell-FCGR tests do not allow for grain boundary or $\delta$ phase oxidation and as a result, may make the $\delta$ phase less susceptible to dwell fatigue crack propagation resulting in a fracture mode that is predominately transgranular, as can be seen in Figure 7 .

Although not as prevalent as the $\delta$ phase crack propagation phenomena, two types of round/globular particles were also sparingly observed along the dwell fatigue crack path. These particles appeared to be dark and light-coloured carbides due to atomic number contrast when imaged with the SEM BSE detector. EDX spot analysis, shown in Figure 11, illustrates that both of these particles were Nb-rich carbides. The difference between the two particles was that the darker-coloured carbides were heavily oxidized and located behind the crack front. In comparison, the lighter-coloured carbides showed no evidence of oxidation and were predominantly observed in crack-free grain boundary locations or just ahead of the crack tip, as shown in Figure 11. These observations are in agreement with other studies that have also observed in Nb-containing superalloys that oxidation of $\mathrm{NbC}$ particles near grain boundaries has been linked to environmental susceptibility during fatigue crack propagation [13]. 

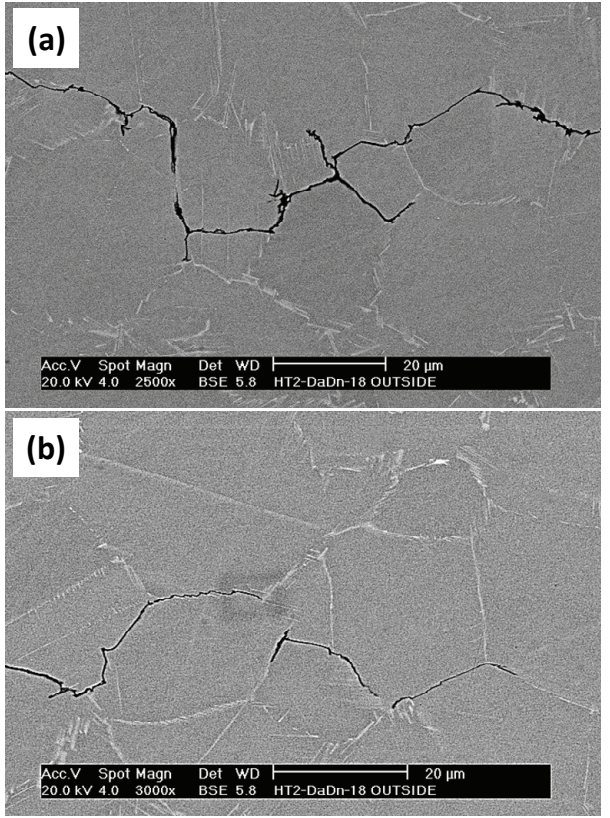

Figure 9: Cross-sectional examination of the interrupted HT2 dwell-FCGR specimen using BSE imaging showing clear evidence of the predominantly intergranular fracture mode. It should be noted that under BSE imaging, the $\delta$ phase appears light (white) coloured.

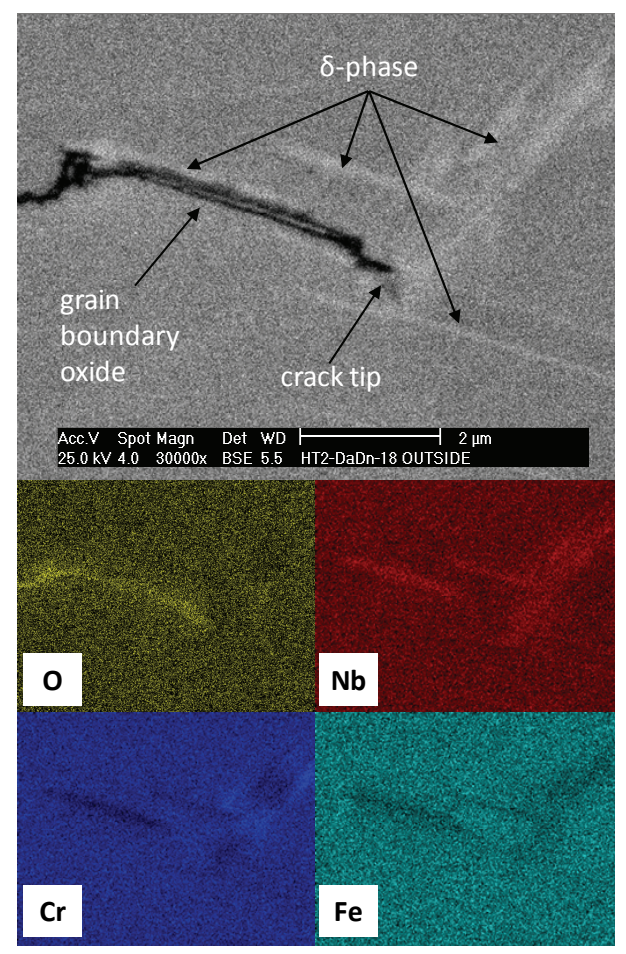

Figure 10: Energy dispersive x-ray map of a representative crack tip and neighboring $\delta$ phase observed in a polished 718Plus dwellFCGR fracture specimen observed under the BSE detector.
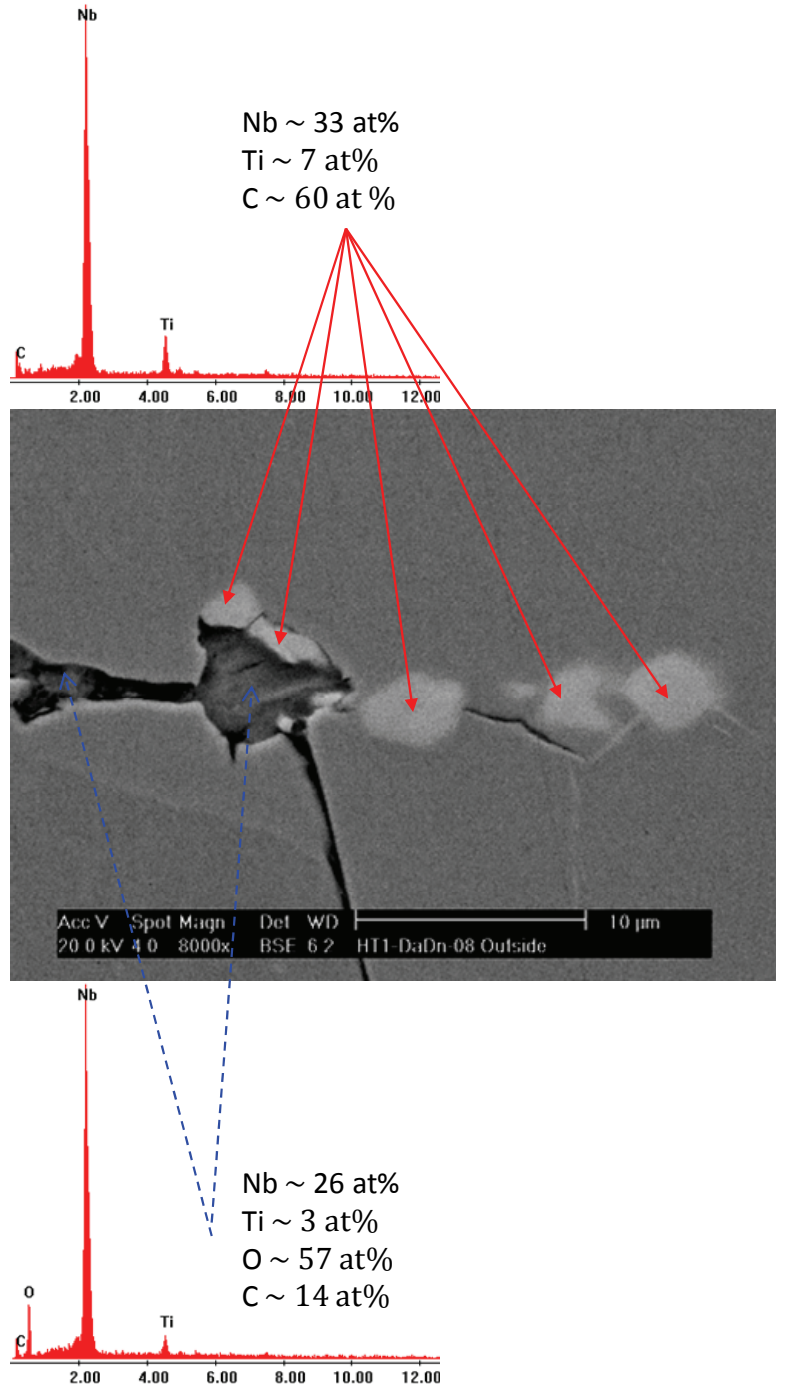

Figure 11: Energy dispersive $\mathrm{x}$-ray analysis of representative carbide phases found along the dwell fatigue crack propagation path of tested 718Plus specimens.

\section{Summary and Conclusions}

FCGR and dwell-FCGR tests were conducted in a vacuum environment and these results were compared with data obtained under identical test parameters with the exception of a lab air environment. The results were examined to elucidate the environmental and dwell effect on crack propagation for various microstructural conditions of 718Plus and Waspaloy. The vacuum FCGR test results obtained in this study demonstrated that under an inert environment, the FCGR behaviour of 718Plus and Waspaloy are identical in the near-threshold region and in the steady-state Paris regime. Comparison with lab air test results indicated that environmental effects have a significant impact on the FCGR characteristics of both alloys, particularly in the nearthreshold regime. The higher stress-intensity threshold behaviour observed in the lab air tests appears to be a result of an oxidationrelated phenomenon. The dwell fatigue crack propagation 
behaviour of HT1, HT2 and W1 under vacuum conditions displayed identical behaviour irrespective of differences in microstructural and processing features. For all three material conditions tested under vacuum, the crack growth rates decreased dramatically compared to lab air test results, highlighting the crucial impact of environmental damage on the dwell-fatigue crack propagation resistance of both 718Plus and Waspaloy.

Post-fracture analysis of the vacuum and lab air FCGR and dwellFCGR specimens was performed and compared with respect to deformation damage modes. It was found that the fracture mode for the standard heat treatment, HT1 condition of 718Plus was predominately intergranular in both the FCGR and dwell-FCGR test conditions, whereas the thermally exposed HT2 condition exhibited a larger fraction of transgranular failure than HT1 under non-dwell FCGR testing circumstances. The Waspaloy non-dwell and dwell-FCGR fracture surfaces revealed a predominantly transgranular deformation mode, significantly different to the 718Plus HT1 and HT2 conditions. Comparison of the fracture surfaces of the FCGR and dwell-FCGR tests that were performed in vacuum revealed that the observed differences in fracture mode present in lab air tested specimens were no longer present under the inert environment. The fracture surfaces of HT1, HT2 and W1 all exhibited transgranular fracture under vacuum and were nearly indistinguishable in crack topography, further reinforcing the identical measured crack growth rates.

Cross-sectional analysis of interrupted dwell-FCGR tests conducted in lab air also showed that the crack propagation of HT1 and HT2 was intergranular in nature. Based on the observed fracture morphology of HT1, HT2, and W1, it can be deduced that the damage mechanism for 718Plus is predominantly a timedependent process, whereas in Waspaloy, cycle-dependent damage mechanisms appear to dominate during crack propagation.

The dynamic embrittlement process, which is believed to be the governing mechanism for intergranular failure of 718Plus, involves short-range atomic oxygen diffusion (or other gaseous species) into the grain boundaries, which lead to grain boundary decohesion. The preferred crack path in this study observed for 718 Plus was along the susceptible (parallel) grain boundary $\delta$ phase. It appears that the presence of grain boundary $\delta$ phase in 718Plus may play some role in preferential intergranular cracking when compared to Waspaloy. The observed improved dwellfatigue crack propagation resistance of HT2 in the present study may be strongly related to the coarsening of the $\gamma^{\prime}$ hardening phase during thermal exposure, with potential further improvement via implementation of a bimodal $\gamma^{\prime}$ heat treatment.

EDX analysis verified the presence of the $\delta$ phase along the dwell fatigue cracks in 718Plus and showed that the $\delta$ phase just at the crack tip may have become oxidized which may be a contributing factor in the susceptibility of the grain boundaries during the dwell-FCGR tests. Also, spot analysis revealed the presence of $\mathrm{Nb}$-rich carbides along the dwell-fatigue crack path of 718Plus. Carbides located behind the crack front were heavily oxidized and those carbides observed in crack-free grain boundary locations or just ahead of the crack tip contained no oxidation. It is believed that oxidation of these $\mathrm{NbC}$ particles near grain boundaries may be linked to the environmental susceptibility of 718Plus during dwell-fatigue crack propagation.

\section{References}

1. R.L. Kennedy, "Allvac ${ }^{\circledR} 718$ Plus ${ }^{\circledR}$, Superalloy for the Next Forty Years," Superalloys 718, 625, 706 and Various Derivatives 2005, ed. E.A. Loria, (Warrendale, PA: The Minerals, Metals and Materials Society, 2005) 1-14.

2. W. D. Cao, "Role of Chemistry in 718-Type Alloys: Allvac ${ }^{\circledR}$ 718Plus ${ }^{\circledR}$, Alloy Development”, Superalloys 2004, ed. K.A Green, T.M Pollock, and H. Harada, (Warrendale, PA: The Minerals, Metals and Materials Society, 2004) 91-99.

3. E.T. McDevitt and J. Bentley; Supplemental Proceedings: Vol. 1: Fabrication, Materials, Processing and Properties; Materials for High Temperature Applications: Next Generation Superalloys and Beyond; TMS Annual Meeting (2009).

4. R.M. Kearsey and J. Tsang, "Systematic Evaluation of Microstructural Effects on the Mechanical Properties of ATI 718Plus ${ }^{\circledR}$ Alloy - Part I: Axial Fatigue,” (Report NRC-LTRSMPL-2011-0056, National Research Council of Canada, Institute for Aerospace Research, Jan. 2011).

5. J. Tsang and R.M. Kearsey, "Systematic Evaluation of Microstructural Effects on the Mechanical Properties of ATI 718Plus ${ }^{\circledR}$ Alloy - Part II: Fatigue Crack Growth Behaviour," (Report NRC-LTR-SMPL-2011-005, National Research Council of Canada, Institute for Aerospace Research, Jan. 2011).

6. W. Cao, "Thermal Stability Characterization of Ni-Base ATI 718Plus ${ }^{\circledR}$ Superalloy,” Superalloys 2008, ed. R. Reed, K. Green, P. Caron, T. Gabb, M. Fahrmann, E. Huron, S. Woodward, (Warrendale, PA: The Minerals, Metals and Materials Society, 2008), 789-798.

7. R.M. Kearsey, J. Tsang, S. Oppenheimer, and E. McDevitt, "Systematic Evaluation of Microstructural Effects on the Mechanical Properties of ATI 718Plus ${ }^{\circledR}$ Alloy”, Superalloys 718 and Derivatives 2011, ed. E.A. Ott et al. (Warrendale, PA: The Minerals, Metals and Materials Society, 2011) 781797.

8. "Standard Test Method for Measuring Fatigue Crack Growth Rates," American Society for Testing and Materials (ASTM) E647-05.

9. J.L. Yuen, P. Roy, and W.D. Nix, "Effect of oxidation kinetics on the near threshold fatigue crack growth behaviour of a nickel base superalloy”, Metall. Trans. A, Vol. 15A, No. 9 (1984), 1769-1775.

10. S. Suresh, G.F. Zamiski, and O. Ritchie, "Oxide induced crack closure: an explanation for near threshold corrosion fatigue crack growth behavior”, Metall. Trans. A, Vol. 12A, (1981), 1435-1443.

11. X. Liu, S. Rangararan, E. Barbero, K. Chang, W. Cao, R. Kennedy, and T. Carneiro, "Fatigue Propagation Behaviour of Newly Developed Allvac 718Plus Superalloy, Superalloys 2004, ed. K.A Green, T.M Pollock, and H. Harada, (Warrendale, PA: The Minerals, Metals and Materials Society, 2004), 283-290.

12. C. Moura Branco, A. Sousa e Brito, and J. Byrne, "Life Extension Methodology Based on Creep-Fatigue Models", 
Paper presented at RTO AVT Workshop, Greece, 5-6 October 1998, RTO MP-17.

13. M.J. Starink and P.A.S. Reed, "Thermal activation of fatigue crack growth: analyzing the mechanisms of fatigue crack propagation in superalloys”, Mater. Sci. Eng. A, 491 (2008), 279-289.

14. U. Krupp, W. Kane, J.A. Pfaendtner, X. Liub, C. Laird, and C.J. McMahon Jr., "Oxygen-Induced Intergranular Fracture of the Nickel-Base Alloy IN718 During Mechanical Loading at High Temperatures, Mat. Research Vol. 7, No.1 (2004), 3541.

15. T.P. Gabb, J. Telesman, A. Garg, P. Lin, V. Provenzano, R. Heard, and H.M. Miller, "Grain Boundary Engineering the Mechanical Properties of Allvac 718Plus Superalloy”, (Report NASA/TM-2010-216935, National Aeronautics and Space Administration, Glen Research Center, Dec. 2010). 